\title{
STUDI MENGENAI PENINGKATAN SIKAP PENGGUNA SHOPEE MELALUI KEPERCAYAAN
}

\author{
Annisa Rizky Nur Fitriana ${ }^{1}$, Yudha Trishananto ${ }^{2}$ \\ 1,2Institut Agama Islam Negeri Salatiga, fannisa793@gmail.com, \\ yudhatrishananto@iainsalatiga.ac.id
}

\begin{abstract}
ABSTRAK
Penelitian ini bertujuan untuk mengetahui Sikap Belanja Online di Shopee Dipengaruhi Oleh Islamic branding, perceived benefit dan electronic word of mouth melalui Kepercayaan. Penelitian dilakukan dengan metode kuantitatif. Populasi yang digunakan yaitu pelanggan aplikasi shopee. Sampel yang digunakan adalah pelanggan yang pernah memakai aplikasi shopee ketika berbelanja online dengan jumlah sampel sebanyak 95 orang. Langkah pengambilan sampel dengan purposive sampling. Penelitian yang dilakukan dengan analisis regresi linier berganda melalui bantuan aplikasi SPSS 25.0. Hasil yang diperoleh Islamic branding, perceived benefit dan electronic word of mouth terdapat pengaruh positif serta tidak signifikan terhadap kepercayaan, Islamic Branding, dan perceived benefit terdapat pengaruh positif terhadap sikap belanja online. electronic word of mouth terdapat pengaruh positif serta tidak signifikan terhadap sikap belanja online. Kepercayaan berpengaruh positif dan tidak signifikan terhadap sikap belanja online. Adanya kepercayaan tidak mampu menjadi mediasi pengaruh Islamic branding, perceived benefit dan electronic word of mouth terhadap sikap belanja online.
\end{abstract}

Kata kunci: Islamic branding, perceived benefit dan electronic word of mouth, Kepercayaan, Sikap Belanja Online.

\begin{abstract}
ABSTRACK
This study aims to determine the Attitude of Online Shopping at Shopee Influenced by Islamic Brands, Perceived Benefits and Electronic Word of Mouth through Trust. The research was conducted using quantitative methods. The population used is the shopee application customers. The sample used is customers who have used the Shopee application when shopping online with a total sample of 95 people. The sampling step is purposive sampling. The research was conducted with multiple linear regression analysis through the help of the SPSS 25.0 application. The results obtained by Islamic brands, perceived benefits and electronic word of mouth have a positive and insignificant effect on trust, Islamic brands and perceived benefits have a positive influence on online shopping attitudes. Electronic word of mouth has a positive and insignificant effect on online shopping attitudes. Trust has a positive and insignificant effect on online shopping attitudes. The existence of trust is not able to mediate the influence of Islamic brands, perceived benefits and electronic word of mouth on online shopping attitudes.
\end{abstract}

Keywords: Islamic Branding, Perceived Benefit, Electronic Word of Mouth, Trust, Online Shopping Attitude

Naskah diterima : 24-05-2021, Naskah dipublikasikan : 28-09-2021 


\section{PENDAHULUAN}

Pada era saat ini adanya internet merupakan sebuah fasilitas yang menjadi hal penting dalam kehidupan masyarakat. Dalam kehidupan sehari-hari sebagian dari masyarakat akan sedikit melungkan waktu agar dapat membuka jaringan internet. Hal ini dikarenakan internet telah memunculkan metode yang terbaru agar dapat menarik perhatian pelanggan (Putri \& Rizki, 2018).

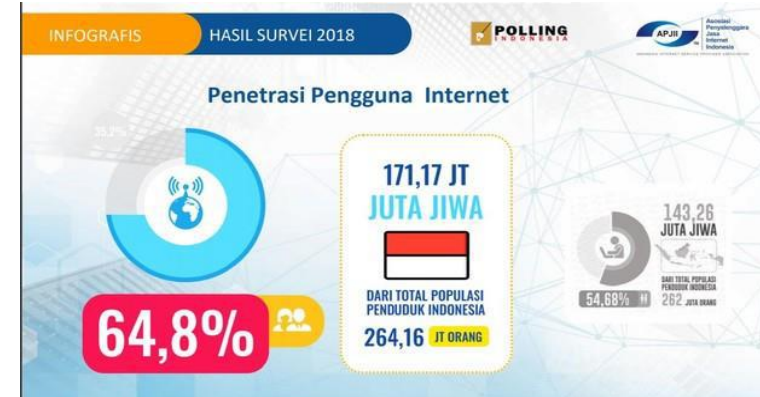

Gambar 1. Pengguna Internet Negara Indonesia

Sumber: (Asosiasi Jasa Pengelola Internet Indonesia, 2018)

Pada gambar 1. Dapat diamati telah terjadi peningkatan yang signifikan pemakaian internet yang ada di Indonesia apabila dibandingkan dengan penggunaan pada tahun-tahun sebelumnya. Dikarenakan naiknya penggunaan internet membuat pengusaha-pengusaha lebih meningkatkan pembaruan dalam e-commerce (Putri \& Rizki, 2018).

Saat ini pasar electronic commerce Indonesia didominasi oleh suatu marketplace shopee yang awalnya dari negara Singapura. Munculnya aplikasi shopee terkenal oleh banyak lingkungan sebab akan lebih mudah ketika seseorang memiliki keinginan untuk mencari, berbelanja maupun menjual sebuah produk melalui bantuan ponsel (Samuri et al., 2018). Shopee merupakan aplikasi secara online dibuat oleh Chris Feng tahun 2015 yang lalu pada negara Singapura kemudian seiring berjalannya waktu semakin meluas jangkauannya ke negara lain seperti Thailand, Taiwan, Malaysia dan Indonesia. Shopee adalah aplikasi berbelanja secara online yang utama yang banyak dipakai serta memperoleh marketplace yang banyak dipakai pelanggan negara Indonesia (Samuri et al., 2018). Suatu sikap dapat dimaknai sebagai bentuk respon positif maupun negatif yang diproleh dari sesuatu. Jika reaksinya baik akan terdapat keinginan untuk lebih bertahan ataupun sebaliknya (Engriani, Yunita \& Aulia, 2019). Keterkaitan antara kepercayaan dengan sikap sangatlah erat dikarenakan mudah berubah-ubah. Jika sikap berjalan secara lanjut akan mendapatkan suatu kepercayaan yang tinggi dari konsumen. Sikap dari seseorang juga dapat berganti pada waktu tertentu. Jika kepercayaan semakin tinggi terhadap suatu situs berbelanja online artinya sikap positif konsumen juga akan semakin meningkat (Engriani, Yunita \& Aulia, 2019).

Indonesia yakni satu dari negara Muslim yang besar di dunia, sehingga menjadikan pasar mempunyai suatu potensi bagi pengusaha-pengusaha, terutama adalah pengusaha yang mengambil manfaat dari e-commerce. Langkah yang dapat dilakukan agar konsumen tertarik membeli produk yang mereka gunakan adalah dengan adanya Islamic branding yakni dengan mengambil manfaat identitas Islam untuk memberikan merek dalam sebuah produk. Manfaat yang dirasakan dikatakan memberikan kepuasan jika konsumen dapat merasakan apa yang didapatkan dari produk yang telah dibeli. Kesesuaian konsumen dengan keinginannya akan mempengaruhi minat kosumen untuk membeli kembali di lain hari. (Engriani \& Aulia, 2019). Munculnya teknologi internet yang semakin berkembang menyebabkan pembeli lebih memberi perhatian kepada electronic word of mouth jika ingin berbelanja melalui media aplikasi internet. 
Di tempat tersebut hadir berbagai macam tanggapan tentang produk yang ingin dibeli, baik bersifak baik maupun tidak baik.

Berdasarkan penelitian terdahulu ditemukan adanya perbedaan, penelitian oleh Kirana (2017) bahwa adanya perceived benefit mampu memberikan pengaruh positif terhadap sikap belanja online, penelitian oleh Nasution (2019) bahwa adanya percived benefit mampu memberikan pengaruh positif serta signifikan terhadap sikap belanja online dengan marketplace sedangkan oleh Mevionita (2017) bahwa perceived benefit tidak ditemukan pengaruh yang positif serta signifikan terhadap sikap belanja online. Sesuai research GAP yang telah dipaparkan dibutuhkan penelitian lanjutan sebab terjadinya hasil yang tidak konsisten jika melakukan penelitian yang selanjutnya maka hasil akan lebih sesuai. Sesuai dengan latar belakang yang diuraikan terdapat rumusan masalah yang didapatkan yaitu: Bagaimana pengaruh Islamic branding, perceived dan electronic word of mouth terhadap kepercayaan belanja online di shopee? Bagaimana pengaruh Islamic branding, perceived benefit, electronic word of mouth dan kepercayaan terhadap sikap belanja online di shopee? Bagaimana pengaruh Islamic branding, perceived dan electronic word of mouth terhadap sikap belanja online di shopee melalui kepercayaan sebagai variabel intervening?. Hasil penelitian yang dilakukan diharapkan dapat mengetahui Peningkatan Sikap Pengguna Shopee Melalui Kepercayaan.

\section{KAJIAN LITERATUR}

\section{Technology Acceptance Model (TAM)}

Technology Acceptance Model (TAM) yakni bentuk model penerimaan sistem informasi yang di manfaatkan user (Marchelina \& Pratiwi, 2018). TAM mampu memberi dasar agar memperoleh pengaruh dari faktor luar terhadap kepercayaan, sikap serta tujuan pemakaiannya. TAM merupakan bentuk model penelitian paling terkenal yang dapat memberi asumsi kegunaan serta penerimaan individu dalam berkembangnya teknologi serta informasi (Witami \& Suartana, 2019). Keterkaitan antara Technology Acceptance Model (TAM) dengan penelitian ini yakni dapat memperoleh penjelasan pada sikap konsumen saat berbelanja online dagan shopee.

\section{Kepercayaan}

Kepercayaan adalah tindakan yang menampakkan perasaan suka dan rajin saat memanfaatkan suatu bentuk produk atau merek (Gunawan, 2011). Kepercayaan merupakan hal yang sentral saat seseorang membeli dengan bantuan media sosial. Jika kepercayaan tidak ada maka tidak ada kemungkinan seorang konsumen untuk membeli secara online. Kepercayaan berkaitan erat jika dihubungkan dengan sikap dari konsumen sehingga jika ingin membentuk suatu kepercayaan di dalam pemikiran konsumen cukup sulit (Istanti, 2017). Untuk mengukur suatu kepercayaan dapat menggunakan beberapa indikator yakni: terjaminnya kepuasan, perhatian, adanya keterus-terangan (Sukma, 2012).

\section{Sikap Belanja Online}

Sikap belanja online yakni sesuatu yang diabayangkan maupun hal yang diperoleh pelanggan mengenai baik maupun buruknya jika melakukan suatu transaksi belanja dengan online. Munculnya sebuah sikap dapat memberikan suatu pengaruh seseorang jika memilih sesuatu yang mereka anggap benar maaupun yang dianggap salah karena sikap adalah sebuah keadaan emosi yang dimiliki seseorang (Azwar, 2013).

Terdapat beberapa faktor yang dapat digunakan untuk sikap belanja online seperti: kualitas web yang dipersepsi, manfaat yang diperoleh konsumen, electronic word of mouth, kepercayaan. Untuk mengukur sikap belanja online dapat menggunakan beberapa indikator seperti belanja secara online adalah gagasan yang baik, belanja secara online akan lebih lebih baik 
dari belanja secara offline, belanja secara online merupakan hal yang menyenangkan (Yunita \& Aulia, 2019).

\section{Islamic Branding}

Islamic branding yakni penggunaan nama dalam sebuah produk hubungannya pada Islam maupun dapat mengarah untuk identitas yang halal dari suatu produk (Tai \& Chew., 2012). Adanya Islamic branding dapat memberikan beberapa manfaat untuk konsumen yakni memberikan kemudahan bagi konsumen jika ingin meneliti produk serta jasa, memberi kemudahan bagi konsumen agar mendapatkan kualitas yang sesuai jika seseorang hendak membeli lagi dikemudian hari dengan harga yang sesuai (Yunus et al., 2014). Mengukur Islamic branding dapat menggunakan beberapa indikator seperti pentingnya sebuah merek, keakraban merek, kepercayaan dari konsumen yang membutuhkan, adanya label halal (Yunus et al., 2014).

\section{Perceived Benefit}

Perceived benefit adalah seberapa besar suatu teknologi dari e-commerce dapat membantu konsumen saat melakukan transaksi belanja online, sehingga nantinya transaksi yang dilakukan akan lebih mudah, dapat menghemat waktu dan lebih efisien sehingga konsumen dapat memperoleh manfaaat yang diinginkan (Pekerti, 2016). Mengukur perceived banefit dapat menggunakan beberapa indikator yakni terdapat waktu 24 jam, informasi produk yang rinci, informasi produk, sunber dari konsumen yang pernah melakukan transaksi, produk unik serta baru, macam - macam cara membayar (Pekerti, 2016).

\section{Electronic Word of Mouth}

EWOM diartikan bentuk tukar-menukar informasi maupun pengetahuan secara online dalam media sosial (Charo et al., 2015). Adanya internet mengakibatkan langkah baru ketika berkomunikasi yang dapat membantu konsumen dan perusahaan dalam berkomunikasi. Penyebaran informasi melalui EWOM dapat dilakukan melalui media facebook, chat room, instagram, serta jenis sosial media yang lain. Melalui komunikasi dengan online dapat membantu konsumen ketika berbagi pengalaman pada suatu produk maupun jasa (Charo et al., 2015). Beberapa dimensi-dimensi EWOM antara lain kredibilitas sumber, kualitas argumen, tipe review, recommendation framing (valence), recommendation sidednes, volume review, disconfirming information, kekuatan argumen, konsistensi rekomendasi, peringkat rekomendasi, panjang review, visual cue dan penyebaran. Mengukur electronic word of mouth dapat menggunakan beberapa indikator yakni intensitas, konten, valensi opini. 


\section{Kerangka pemikiran}

Sesuai dengan teori serta penelitian yang lalu mengenai Sikap Belanja Online dipengaruhi oleh Islamic Branding, Perceived Benefit dan Electronic Word of Mouth melalui Kepercayaan maka diperoleh kerangka pemikiran sebagai berikut:

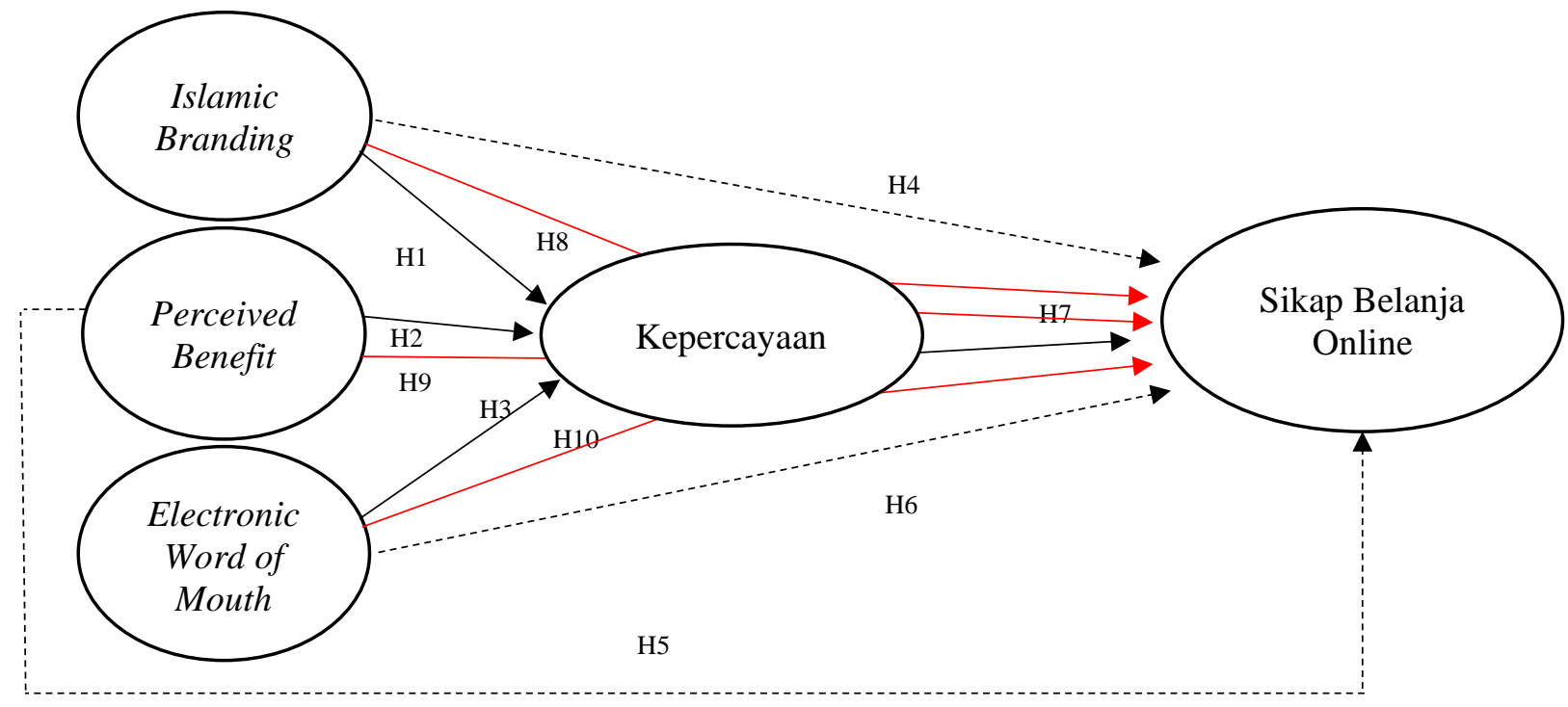

\section{Hipotesis}

Gambar 2. Kerangka Pemikiran

Sesuai telaah pustaka maupun kerangka pemikiran, diperoleh hipotesis penelitian yakni:

Penelitian oleh Rakhmawati (2015) menyatakan Islamic branding mazaya sebagai make up halal ditemukan pengaruh yang signifikan terhadap kepercayaan. Hipotesis yang didapatkan yakni:

HI = Islamic branding memiliki pengaruh positif serta signifikan terhadap kepercayaan belanja online di shopee.

Penelitian oleh Faradilla (2016) menyatakan perceived benefit terdapat pengaruh positif serta signifikan terhadap kepercayaan pengunjung toko online berrybenka.com. Hipotesis yang didapatkan yakni:

H2 = Perceived benefit memiliki pengaruh positif serta signifikan terhadap kepercayaan belanja online di shopee.

Penelitian oleh Zalni (2019) menyatakan electronic word of mouth terdapat pengaruh positif serta signifikan terhadap kepercayaan dari pengguna shopee kota Padang. Hipotesis yang didapatkan yakni:

H3 = EWOM memiliki pengaruh positif serta signifikan terhadap kepercayaan belanja online di shopee.

Penelitian oleh Sudarmawan et al. (2016) menyatakan Islamic branding terdapat pengaruh positif terhadap sikap konsumen Muslim saat mengkonsumsi merek Islami minuman ringan.

Hipotesis yang didapatkan yakni:

H4 = Islamic branding memiliki pengaruh positif serta signifikan terhadap sikap belanja online.

Penelitian oleh Triwidyastika (2012) menyatakan perceived benefit terdapat pengaruh positif terhadap sikap belanja secara online $D$ 'shetwo boutique. Hipotesis yang didapatkan yakni: H5 = Perceived benefit memiliki pengaruh positif serta signifikan terhadap sikap belanja online di shopee.

Penelitian oleh Kirana (2017) menyatakan electronic word of mouth terdapat pengaruh 
positif terhadap sikap belanja online di Lazada. Hipotesis yang dapat diperoleh yakni:

H6 = EWOM memiliki pengaruh positif serta signifikan terhadap sikap belanja online di shopee.

Penelitian oleh Sidharta, I. \& Suzanto (2015) menyatakan kepercayaan terdapat pengaruh signifikan terhadap sikap belanja online e-commerce. Hipotesis yang didapatkan yakni:

H7 = Kepercayaan memiliki pengaruh positif serta signifikan terhadap sikap belanja online di shopee.

Penelitian oleh Sudarmawan et al. (2016) menyatakan Islamic branding terdapat pengaruh yang positif terhadap sikap konsumen Muslim saat mengkonsumsi merek Islami minuman ringan dan penelitian oleh (Rakhmawati, 2015) menyatakan Islamic branding mazaya sebagai make up halal ditemukan pengaruh signifikan terhadap kepercayaan. Hipotesis yang didapatkan yakni:

H8 = Kepercayaan dapat menjadi mediasi Islamic branding terhadap sikap belanja online di shopee.

Penelitian oleh Nasution (2019) menyatakan perceived benefit terdapat pengaruh positif serta signifikan terhadap sikap belanja secara online melalui marketplace serta oleh Faradilla (2016) menyatakan persepsi manfaat memiliki pengaruh signifikan terhadap kepercayaan.

Hipotesis yang didapatkan yakni:

H9 = Kepercayaan dapat menjadi mediasi perceived benefit terhadap sikap belanja online di shopee.

Penelitian oleh Madjid, et al. (2018) bahwa kepercayaan memediasi secara penuh pengaruh EWOM terhadap sikap belanja online. Hipotesis yang didapatkan yakni:

H10 = Kepercayaan dapat menjadi mediasi EWOM terhadap sikap belanja online di shopee.

\section{METODE PENELITIAN}

Penelitian dilaksanakan melalui metode kuantitatif diartikan sebagai metode dimanfaatkan ketika melakukan penelitian untuk populasi maupun sampel tertentu. Teknik pengambilan data yakni menggunakan bantuan kuesioner. Populasi yang dipakai adalah pelanggan aplikasi shopee. Jumlah populasi yang digunakan tidak diketahui jumlahnya dengan pasti. Sampel yang diambil yakni pelanggan yang pernah memakai aplikasi shopee saat berbelanja online dengan jumlah sampel 95 orang. Langkah mengambil sampel yang dipakai yakni purposive sampling. Penelitian ini, memakai alat analisis regresi linier berganda melalui bantuan SPSS 25.0.

\section{HASIL DAN PEMBAHASAN}

Uji Validitas

Tabel 1. Hasil Uji Validitas

\begin{tabular}{|c|c|c|c|}
\hline Variabel & $\begin{array}{r}\text { Item } \\
\text { pertanyaan }\end{array}$ & R hitung & $R$ tabel \\
\hline \multirow{4}{*}{$\begin{array}{l}\text { Islamic } \quad \text { Branding } \\
\text { (X1) }\end{array}$} & 1 &, $350^{* *}$ & 0,2017 \\
\hline & 2 &, $461^{* *}$ & 0,2017 \\
\hline & 3 &, $720^{* *}$ & 0,2017 \\
\hline & 4 &, $543^{* *}$ & 0,2017 \\
\hline \multirow{7}{*}{$\begin{array}{l}\text { Perceived Benefit } \\
\text { (X2) }\end{array}$} & 1 &, $387^{* *}$ & 0,2017 \\
\hline & 2 &, $595^{* *}$ & 0,2017 \\
\hline & 3 &, $449^{* *}$ & 0,2017 \\
\hline & 4 & ,290** & 0,2017 \\
\hline & 5 &, $412^{\text {** }}$ & 0,2017 \\
\hline & 6 &, $555^{* *}$ & 0,2017 \\
\hline & 1 &, $694^{* *}$ & 0,2017 \\
\hline
\end{tabular}




\begin{tabular}{|l|c|c|c|}
\hline \multicolumn{1}{|c|}{ Variabel } & $\begin{array}{c}\text { Item } \\
\text { pertanyaan }\end{array}$ & R hitung & R tabel \\
\hline $\begin{array}{l}\text { Electronic word of } \\
\text { mouth (X3) }\end{array}$ & 2 &, $761^{* *}$ & 0,2017 \\
\cline { 2 - 4 } Kepercayaan (Z) & 3 &, $595^{* *}$ & 0,2017 \\
\cline { 2 - 4 } & 1 &, $559^{* *}$ & 0,2017 \\
\cline { 2 - 4 } & 2 &, $706^{* *}$ & 0,2017 \\
\hline \multirow{2}{*}{$\begin{array}{l}\text { Sikap Belanja Online } \\
\text { (Y) }\end{array}$} & 1 &, $673^{* *}$ & 0,2017 \\
\cline { 2 - 4 } & 2 &, $646^{* *}$ & 0,2017 \\
\cline { 2 - 4 } & 3 &, $772^{* *}$ & 0,2017 \\
\hline
\end{tabular}

Sumber: Data primer, diolah 2021

Dapat diamati bahwa pada setiap item pertanyaan mempunyai $r$ hitung $>r$ tabel dalam hal ini pertanyaan setiap variabel valid.

\section{Uji Reliabilitas}

Tabel 2. Hasil Uji Reliabilitas

\begin{tabular}{|c|l|l|}
\hline No & \multicolumn{1}{|c|}{ Variabel } & Kesimpulan \\
\hline 1. & Islamic Branding (X1) & Reliabel \\
\hline 2. & Perceived Benefit (X2) & Reliabel \\
\hline 3. & Electronic Word of Mouth (X3) & Reliabel \\
\hline & Kepercayaan (Z) & Reliabel \\
\hline 4. & Sikap Belanja Online (Y) & Reliabel \\
\hline
\end{tabular}

Sumber: Data primer, diolah 2021

Dapat diamati setiap variabel tersebut bernilai $>0,6$ artinya semua variabel dapat diterima sebab reliabel.

\section{Uji Asumsi Klasik}

\section{Uji Normalitas}

Langkah agar mengetahui normalitas suatu data dapat memakai uji kolmogorof smirnov test dengan asumsi jika nilai signifikansi > 0,05 artinya data memiliki distribusi normal.

Tabel 3. Hasil Uji Kolmogorov Smirnov

\section{One-Sample Kolmogorov-Smirnov Test}

\begin{tabular}{|c|c|c|}
\hline & & $\begin{array}{l}\text { Unstandardized } \\
\text { Residual }\end{array}$ \\
\hline $\mathrm{N}$ & & 95 \\
\hline \multirow{2}{*}{$\begin{array}{l}\text { Normal } \\
\text { Parameters }\end{array}$} & Mean & ,0000000 \\
\hline & $\begin{array}{l}\text { Std. } \\
\text { Deviation }\end{array}$ & 2,25344230 \\
\hline \multirow[t]{3}{*}{$\begin{array}{c}\text { Most } \\
\text { Differences }\end{array}$} & Absol & ,066 \\
\hline & Positiv & ,049 \\
\hline & Negati &,- 066 \\
\hline \multicolumn{2}{|l|}{ Test Statistic } & ,066 \\
\hline \multicolumn{2}{|c|}{ Asymp. Sig. (2-tailed) } & $200^{\mathrm{c}, \mathrm{d}}$ \\
\hline
\end{tabular}

Sumber: Data primer diolah, 2021 
Sesuai pengujian kolmogorof sminov didapatkan nilai Asym. sig 0,200 sehingga telah memenuhi asumsi normalitas pada model regresi.

\section{Uji Multikolinearitas}

Tabel 4. Hasil Uji Multikolinearitas

\begin{tabular}{|c|c|}
\hline Variabel & VIF Nilai \\
\hline $\begin{array}{r}\text { Islamic } \\
\text { Branding (X1) } \\
\end{array}$ & 1,039 \\
\hline $\begin{array}{l}\text { Perceived } \\
\text { Benefit (X2) }\end{array}$ & 1,105 \\
\hline $\begin{array}{c}\text { Electronic } \\
\text { Word of Mouth (X3) }\end{array}$ & 1,096 \\
\hline (Z) Kepercayaan & 1,060 \\
\hline
\end{tabular}

Sumber: Data primer diolah, 2020

Dapat diamati nilai VIF untuk variabel Islamic branding (X1) sejumlah $1,039<10$, variabel perceived benefit sebesar 1,105 < 10, variabel electronic word of mouth (X3) 1,096 < 10 serta variabel kepercayaan $(Z)$ sebesar $1,060<10$. Sehingga berdasarkan asumsi untuk mengambil keputusan pada uji multikolinearitas maka tidak adanya multikolinearitas pada model regresi.

\section{Uji Heteroskedastisitas}

Tabel 5. Hasil Uji Heteroskedastisitas

\begin{tabular}{|l|c|}
\hline \multicolumn{1}{|c|}{ Variabel } & Sig \\
\hline Islamic branding & 0,209 \\
\hline Perceived benefit & 0,540 \\
\hline $\begin{array}{l}\text { Electronic word of } \\
\text { mouth }\end{array}$ & 0,358 \\
\hline $\begin{array}{l}\text { Sikap belanja } \\
\text { online }\end{array}$ & 0,777 \\
\hline
\end{tabular}

Sumber: Data primer, diolah 2021

Untuk mengambil keputusan pada uji heteroskedastistas glejser yakni mengamati nilai sig. Pada variabel independen dengan absolut residual $>0,05$ artinya tidak adanya heteroskedastisitas. Dapat diamati bahwa nilai signifikasi dari variabel Islamic branding sebesar $0,209>0,05$, perceived benefit sejumlah $0,540>0,05$, electronic word of mouth $0,358>0,05$ serta variabel kepercayaan sejumlah $0,777>0,05$ yang artinya tidak ditemukan gejala heteroskedastisitas.

\section{Uji Koefisien Determinasi $\left(\mathbf{R}^{2}\right)$}

Tabel 6. Hasil Uji Koefisien Determinasi

\begin{tabular}{|l|l|r|l|l|}
\hline Model & R & R Square & $\begin{array}{l}\text { Adjusted R } \\
\text { Square }\end{array}$ & $\begin{array}{l}\text { Std. Error of } \\
\text { the Estimate }\end{array}$ \\
\hline 1 &, $498^{\mathrm{a}}$ & 248 &, 214 & 2,303 \\
\hline
\end{tabular}


Sumber: Data primer, diolah 2021

Dapat diamati bahwa koefisien determinasi $\left(\mathrm{R}^{2}\right)$ sejumlah 0,214 maka kontribusi dalam variabel independen dapat memberi pengaruh variabel dependen sebesar 21,4\% sedangkan sisa yang lain dapat dipengaruhi variabel lain dan variabel tersebut tidak dipakai pada penelitian ini.

Tabel 7. Hasil Uji F

\begin{tabular}{|l|l|l|}
\hline \multicolumn{1}{|c|}{ Variabel } & Nilai F & Sig. \\
\hline Islamic branding & \multirow{2}{*}{7,410} & \multirow{2}{*}{, $000^{\mathrm{b}}$} \\
\cline { 1 - 1 } $\begin{array}{l}\text { Perceived benefit } \\
\text { Electronic wod of } \\
\text { mouth }\end{array}$ & & \\
\cline { 1 - 1 } Kepercayaan & & \\
\hline
\end{tabular}

Sumber: Data primer, diolah 2021

Dapat diamati nilai sig. 0,00<0,05 variabel Islamic branding, perceived benefit, EWOM serta kepercayaan ditemukan pengaruh positif terhadap sikap belanja online di shopee.

Tabel 8. Hasil Uji t

\begin{tabular}{|l|l|r|}
\hline Nama Variabel & T & Sig. \\
\hline Islamic Branding & 1,421 &, 159 \\
\hline Perceived benefit & 1,083 &, 282 \\
\hline Electronic word of mouth &, 917 &, 362 \\
\hline
\end{tabular}

Sumber: Data primer, diolah 2021

Besarnya signifikansi variabel Islamic branding (X1) 0,159>0,05 nilai t hitung yakni $1,421<\mathrm{t}$ tabel 1,986 maka adanya pengaruh yang positif tidak signifikan Islamic branding (X1) terhadap kepercayaan (Z), nilai signifikansi variabel perceived benefit (X2) yakni 0,282 >0,05 nilai t hitung 1,083 < t tabel 1,986 maka adanya pengaruh positif tidak signifikan perceived benefit (X2) terhadap kepercayaan (Z) sedangkan nilai signifikansi variabel electronic word of mouth $0,362>0,05$ nilai $\mathrm{t}$ hitung $0,917<\mathrm{t}$ tabel 1,986 maka ditemukan pengaruh yang positif tidak signifikan electronic word of mouth (X3) terhadap kepercayaan (Z).

Tabel 9. Hasil Uji t

\begin{tabular}{|c|c|c|}
\hline Nama Variabel & & Sig. \\
\hline Islamic Branding &, 703 &, 008 \\
\hline Perceived benefit &, 782 &, 000 \\
\hline Electronic word of mouth & 041 &, 967 \\
\hline Kepercayaan &, 082 &, 282 \\
\hline
\end{tabular}

Sumber: Data primer, diolah 2021

Besarnya signifikansi variabel Islamic branding (X1) yakni 0,008 $<0,05$ t hitung 2,703 $>\mathrm{t}$ tabel 1,986 maka adanya pengaruh yang positif serta signifikan Islamic branding (X1) terhadap sikap belanja online (Y). Besar signifikansi variabel perceived benefit (X2) yakni $0,000<0,05$ serta thitung 3,782 > t tabel 1,986 artinya adanya pengaruh positif serta signifikan perceived benefit (X2) terhadap sikap belanja (Y). Besar signifikansi variabel electronic word 
of mouth $0,967>0,05$ serta thitung $0,041<\mathrm{t}$ tabel 1,986 maka ditemukan pengaruh yang positif tidak signifikan electronic word of mouth (X3) terhadap sikap belanja online (Y) sedangkan besar signifikansi variabel kepercayaan (Z) yakni 0,282 > 0,05 nilai t hitung 1,082 < t tabel 1,986 maka adanya pengaruh yang positif tidak signifikan kepercayaan $(Z)$ terhadap sikap belanja online (Y).

\section{Uji Path}

Model 1

Tabel 10. Hasil Uji Path Analysis Persamaan 1

\begin{tabular}{|r|l|l|c|c|}
\hline & $\mathrm{R}$ & $R$ Square & Adjusted R Square & $\begin{array}{l}\text { Std. Error of the } \\
\text { Estimate }\end{array}$ \\
\hline 1 &, $238^{\mathrm{a}}$ &, 057 &, 025 & 2,213 \\
\hline
\end{tabular}

Sumber: Data primer, diolah 2021

Sesuai tabel diatas diperoleh persamaan:

$Z=\beta 0+\beta 1 X 1+\beta 2 X 2+\beta 3 X 3+e 1$

Diperoleh perhitungan yakni:

$Z=13,246+0,136 \mathrm{X} 1+0,075 \times 2+0,088 \times 3+\mathrm{e} 1$

Model 2

Tabel 11. Hasil Uji Path Analysis Persamaan 2

\begin{tabular}{|l|l|l|c|c|}
\hline Model & $\mathrm{R}$ & R Square & Adjusted $R$ Square & $\begin{array}{l}\text { Std. Error of the } \\
\text { Estimate }\end{array}$ \\
\hline 1 &, $498^{\mathrm{a}}$ &, 248 &, 214 & \multicolumn{2}{|c|}{2,303} \\
\hline
\end{tabular}

Sumber: Data primer, diolah 2021

Sesuai tabel diatas diperoleh persamaan:

$\mathrm{Y}=\beta 0+\beta 1 \mathrm{X} 1+\beta 2 \mathrm{X} 2+\beta 3 \mathrm{X} 3+\beta 4 Z+\mathrm{e} 2$

Diperoleh perhitungan yakni:

$\mathrm{Y}=-1,065+0,272 \mathrm{X} 1+0,274 \mathrm{X} 2+0,004 \mathrm{X} 3+0,118 \mathrm{Z}+\mathrm{e} 2$

Pengaruh Islamic branding (X1) terhadap sikap belanja online $(\mathrm{Y})$ melalui kepercayaan $(\mathrm{Z})$

$\mathrm{t}=\mathrm{p} 2 \mathrm{p} 3: \mathrm{Sp} 2 \mathrm{p} 3=0,01604: 0,02009=0,79840$

Maka t hitung $=0,79840<\mathrm{t}$ tabel 1,986 artinya tidak terdapat pengaruh mediasi.

Pengaruh perceived benefit (X2) terhadap sikap belanja online (Y) melalui kepercayaan $(\mathrm{Z})$

$\mathrm{t}=\mathrm{p} 2 \mathrm{p} 3: \mathrm{Sp} 2 \mathrm{p} 3=0,00885: 0,01094=0,80895$

Maka t hitung $=0,80895<\mathrm{t}$ tabel 1,986 artinya tidak terdapat pengaruh mediasi.

Pengaruh electronic word of mouth terhadap sikap belanja online $(\mathrm{Y})$ melalui kepercayaan $(\mathrm{Z})$ $\mathrm{t}=\mathrm{p} 2 \mathrm{p} 3: \mathrm{Sp} 2 \mathrm{p} 3=0,01038: 0,01732=0,59930$

Maka t hitung $=0,59930<\mathrm{t}$ tabel 1,986 artinya tidak terdapat pengaruh mediasi.

\section{Pembahasan}

Pengujian variabel Islamic branding terhadap kepercayaan belanja online dapat diamati pada uji t tabel 8. diketahui nilai signifikansi variabel Islamic branding (X1) 0,159>0,05 nilai t hitung yakni $1,421<\mathrm{t}$ tabel 1,986. Sehingga Islamic branding ditemukan pengaruh positif serta tidak signifikan terhadap kepercayaan dikarenakan pelanggan shopee lebih mementingkan serta memperhatikan aspek-aspek lain yang dapat mempengaruhi kepercayaan dari konsumen seperti kebutuhan dari produk yang akan dibeli serta keinginan untuk membeli. Hasil akhir dalam penelitian sejalan dengan penelitian oleh Ali (2010) bahwa adanya Islamic branding tidak 
ditemukan pengaruh signifikan terhadap kepercayaan, konsumen akan mencari informasi mengenai produk apakah benar halal serta tepat dengan kebutuhan yang diperlukan.

Pengujian variabel perceived benefit terhadap kepercayaan dapat diamati pada uji t tabel 8. diketahui nilai signifikansi variabel perceived benefit (X2) 0,282>0,05 serta nilai t hitung $1,083<\mathrm{t}$ tabel 1,986. Maka perceived benefit ditemukan pengaruh positif serta tidak signifikan terhadap kepercayaan. Ketika membeli suatu produk perceived benefit dapat dianggap penting namun hal tersebut tidak dapat mempengaruhi kepercayaan konsumen hal ini karena konsumen lebih percaya bahwa ketika membeli produk secara offline akan lebih memperoleh manfaat. Hasil akhir dalam penelitian sejalan dengan penelitian oleh Yunita \& Aulia (2019) bahwa tidak ditemukan pengaruh yang signifikan antara perceived benefit terhadap rasa percaya seseorang. Pengujian variabel $E W O M$ terhadap kepercayaan dapat diamati pada uji t tabel 8. diketahui nilai signifikansi variabel EWOM 0,362>0,05 serta nilai t hitung 0,917 < t tabel 1,986. Maka EWOM ditemukan pengaruh positif serta tidak signifikan terhadap kepercayaan. Dengan EWOM memang dapat mempermudah komunikasi ketika ingin memilih suatu produk maupun ingin melihat review namun masyarakat masih kurang percaya dengan hal tersebut dan lebih percaya ketika berkomunikasi secara langsung. Hasil akhir dalam penelitian sejalan dengan penelitian oleh Octavini (2018) bahwa tidak ditemukan pengaruh yang postif EWOM terhadap kepercayaan membeli lewat online.

Pengujian variabel Islamic branding terhadap sikap belanja online dapat dilihat pada uji $\mathrm{t}$ tabel 9. diketahui signifikansi variabel Islamic branding (X1) 0,008 $<0,05$ serta t hitung 2,703 $>\mathrm{t}$ tabel 1,986. Maka Islamic branding ditemukan pengaruh positif serta signifikan terhadap sikap belanja online. Sebelum mengambil sikap untuk membeli produk konsumen yang beragama Islam akan mempertimbangkan Islamic branding, sebab dalam Islam terdapat larangan mengkonsumsi barang-barang yang haram. Hasil akhir dalam penelitian sejalan dengan penelitian Samidi, Sudarmawan et al. (2016) bahwa adanya Islamic branding dapat memberi pengaruh positif serta signifikan pada sikap konsumen muslim untuk mengkonsumsi merek Islami sebuah minuman ringan. Pengujian variabel perceived benefit terhadap sikap belanja online dapat dilihat pada uji $\mathrm{t}$ tabel 9. Besar signifikansi variabel perceived benefit (X2) yakni 0,000 $<0,05$ serta thitung 3,782 $>\mathrm{t}$ tabel 1,986. Sehingga perceived benefit ditemukan pengaruh positif serta signifikan terhadap sikap belanja online. Perceived benefit akan dipikirkan konsumen sebelum membeli sebab apabila seseorang memperoleh perceived benefit sesuai dengan yang diinginkan konsumen mengambil sikap membeli. Hasil akhir dalam penelitian sejalan dengan penelitian oleh Nasution (2019) yakni antara perceived benefit dengan sikap belanja online ditemukan pengaruh yang positif serta signifikan.

Pengujian variabel $E W O M$ terhadap sikap belanja online dapat diamati pada uji t tabel 9. Besar signifikansi variabel EWOM 0,967 > 0,05 serta t hitung 0,041 < t tabel 1,986 maka EWOM memiliki pengaruh positif serta tidak signifikan terhadap sikap belanja online di shopee. Hasil akhir dalam penelitian sejalan dengan penelitian Lee et al. (2008) yakni komentar pelanggan dengan EWOM tidak berpengaruh signifikan terhadap sikap belanja online. Pengujian variabel kepercayaan terhadap sikap belanja online dapat diamati pada uji t tabel 9. Besar signifikansi variabel kepercayaan $(Z)$ yakni $0,282>0,05$ serta nilai t hitung 1,082 < t tabel 1,986 sehingga kepercayaan memiliki pengaruh positif dan tidak signifikan terhadap sikap belanja online di shopee. Keterkaitan antara kepercayaan dengan sikap sangatlah erat dikarenakan mudah berubahubah. Sikap dari seseorang juga dapat berganti pada waktu tertentu. Jika kepercayaan semakin tinggi terhadap suatu situs berbelanja online artinya sikap positif konsumen juga akan semakin meningkat (Engriani, Yunita \& Aulia, 2019). Namun dalam hal ini tidaklah demikian. Hasil akhir dalam penelitian sejalan dengan penelitian oleh Ekawati (2017) bahwa adanya kepercayaan memiliki pengaruh negatif terhadap sikap memakai instagram. 
Adanya kepercayaan tidak mampu memediasi pengaruh Islamic branding terhadap sikap belanja online dapat dilihat pada nilai t hitung $0,79840<$ nilai $t$ tabel 1,986 artinya tidak terdapat pengaruh mediasi. Walaupun adanya Islamic branding ditemukan pengaruh positif terhadap sikap belanja online akan tetapi rasa percaya seorang pelanggan tergantung dari diri masing-masing yang nantinya akan menjadi bahan pertimbangan untuk mengambil sikap pembelian.

Adanya kepercayaan tidak mampu memediasi pengaruh perceived benefit terhadap sikap belanja online dapat dilihat pada nilai t hitung $0,80895<\mathrm{t}$ tabel 1,986 artinya tidak terdapat pengaruh mediasi. Walaupun adanya perceived benefit ditemukan pengaruh yang positif terhadap sikap belanja online akan tetapi kepercayaan akan dipertimbangkannsebelum memutuskan membeli produk secara online. Adanya kepercayaan tidak mampu memediasi pengaruh EWOM terhadap sikap belanja online dapat dilihat nilai $\mathrm{t}$ hitung $0,59930<\mathrm{t}$ tabel 1,986 artinya tidak terdapat pengaruh mediasi. Walaupun adanya EWOM dapat mempermudah dalam memeberikan review akan tetapi rasa percaya seorang pelanggan tergantung dari diri masing-masing yang nantinya akan menjadi bahan pertimbangan untuk mengambil sikap pembelian.

\section{PENUTUP \\ Simpulan}

Sesuai dengan hasil analisis serta beberapa penjelasan yang telah dipaparkan maka diperoleh kesimpulan yakni adanya Islamic branding, perceived benefit serta EWOM ditemukan pengaruh yang positif serta tidak signifikan terhadap kepercayaan disebabkan konsumen shopee kurang percaya kepada adanya Islamic branding, perceived benefit serta EWOM dan keinginan yang diperoleh ketika berbelanja menggunakan aplikasi shopee tidak sesuai dengan harapan. Adanya Islamic branding serta perceived benefit ditemukan pengaruh yang positif serta signifikan terhadap sikap belanja online di shopee sebab konsumen shopee yang beragama Islam memperhatikan adanya aspek Islamic branding sebelum mengambil sikap untuk membeli. Konsumen shopee selalu memperhatikan aspek manfaat yang dirasakan dengan harapan dapat menerima sebuah manfaat atau keuntungan ketika berbelanja online di shopee.

Adanya $E W O M$ memberikan pengaruh yang positif serta tidak signifikan terhadap sikap belanja online di shopee. Konsumen memiliki anggapan bahwa ulasan-ulasan yang dibuat oleh konsumen dalam suatu forum melalui media internet belum tentu sesuai dengan kenyataan yang sebenarnya sehingga konsumen akan melakukan tindakan lain ketika ingin memperoleh informasi sebelum berbelanja secara online. Kepercayaan memiliki pengaruh positif serta tidak signifikan terhadap sikap belanja online. Adanya kepercayaan tidak mampu memediasi pengaruh Islamic branding, pereived benefit serta EWOM terhadap sikap belanja online di shopee.

\section{Saran}

Penelitian ini dilakukan saat pandemi covid-19 melalui penyebaran kuesioner dengan google form maka memungkinkan human error. Penelitian yang akan datang diharapkan lebih baik lagi melalui sumber data yang lebih sesuai dan sumber-sumber yang tepat.

\section{REFERENSI}

Ali, Y. (2015). Australian Multicultural Consumer Diversity: A Study on Muslim Consumers' Perception Towards Halal Labelling. 1-7.

Azwar, S. (2013). Sikap Manusia: Teori dan Pengukurannya. Pustaka Pelajar.

Charo, N., Sharma, P., Shaikh, S., Haseeb, A., and Sufya, M. . (2015). Determining the Impact of E-wom on Brand Image and Purchase Intention through Adoption of Online Opinions. International Journal of Humanities and Management Sciences (IJHMS), 3(1), 2320 4044. 


\section{JURNAL EKOBIS: EKONOMI, BISNIS \& MANAJEMEN}

Ekawati, R. K. (2017). Peran Mediasi Sikap Atas Pengaruh Kepercayaan Terhadap Niat Menggunakan Instagram. Jurnal Sistem \& Teknologi Informasi Komunikasi, 1(1), 1-10.

Engriani, Yunita \& Aulia, N. (2019). The Effect of Perceived Benefit, Electronic Word of Mouth and Perceived Web Quality on Online Shopping Attitude in Shopee With Trust as an Intervening Variable. Journal of Business and Management Research, 124(2), 978-987.

Faradilla, R. S. \& H. S. (2016). Analisis Pengaruh Persepsi Kemudahan Penggunaan dan Persepsi Manfaat Terhadap Minat Beli Dengan Kepercayaan Sebagai Variabel Intervening. Diponegoro Journal of Management, 5(3), 1-12.

Gunawan, F. (2011). Pengaruh Persepsi Merek dan Kepercayaan Konsumen Terhadap Brand Switching Atas Produk Smartphone (Blackberry) Pada Mahasiswa UNP. Jurnal Padang.

Indonesia, A. J. P. I. (2018). No.

Istanti, F. (2017). Pengaruh Harga, Kepercayaan, Kemudahan Berbelanja Dab E-Promosi Terhadap Keputusan Pembelian Belanja Online di Kota Surabaya. Jurnal Bisnis Dan Teknologi Politeknik NSC Surabaya, 4(1), 14-22.

Jumin, Lee., D. H. P. \& I. H. (2016). The Effect of Negative Online Consumer Reviews on Product Attitude: An Information Processing View. Electronic Commerce Research and Applications., 7(5), 341-352.

Kirana, C. D. \& J. M. S. (2017). Pengaruh Kualitas Website, EWOM, Perceived Benefits, Dan Kepercayaan Terhadap Sikap Pada Belanja Online di Lazada.

Madjid Iskandarsyah, Jasman J. Maruf, Mahdani Ibrahim, M. H. (2018). Factors Affecting Online Shopping Attitudes and the Role of Trust as Mediating. International Journal of Management and Economics, 04(9), 1929-1935.

Marchelina, Dwi, dan Pratiwi, R. (2018). Pengaruh Persepsi Manfaat, Persepsi Kemudahan, Persepsi Resiko dan Fitur Layanan Terhadap Minat Penggunaan E- MONEY (Studi Kasus Pada Pengguna E-MONEY Kota Palembang). Jurnal Akuntansi STIE Multi Data Palembang.

Mevionita, P. (2017). Pengaruh Sikap Konsumen Terhadap Belanja Pada Online Shop di Indonesia. Jurnal Ilmiah Mahasiswa Universitas Surabaya, 6(1), 1111-1130.

Nasution, O. B. (2019). Faktor Penentu Sikap Konsumen Untuk Berbelanja Daring Melalui Marketplace. Manajemen, 9(1), 206-214.

Octavini, N. A. (2018). Pengaruh Electronic Word of Mouth dan Pengetahuan Produk Terhadap Kepercayaan dan Dampaknya Pada Keputusan Pembelian Online di Sociolla Pada Mahasiswi S1 Fakultas Ekonomi Dan Bisnis Universitas Muhammadiyah Metro Lampung.

Pekerti, R. I. (2016). Pengaruh Perceived Benefits, Perceived Risks, Hedonic Motivations, Psychological Faktors dan Website Design Terhadap Online Buying Behavior. Jurnal Bisnis Dan Akuntansi, 18(2), 147-158.

Putri, Sri Rahmi \& Rizki, A. (2018). Pengaruh E-WOM Terhadap Citra Perusahaan Dan Dampaknya Terhadap Niat Beli Konsumen Pada Situs Online Shope.id. 3(2), 75-84.

Rakhmawati, A. (2015). Efek Terpaan Iklan CRM (Costumer Relationship Management) di Sosial Media, Branding Mazaya sebagai Make up Halal Terhadap Tingkat Kepercayaan Konsumen. Ilmiah Mahasiswa Universitas Diponegoro, 1-13.

Samidi, Sudarmawan., Dety Nurfadilah, et. al. (2016). The Impact of Islamic Branding on Cunsumer's Attitude Towards Soft Drink Product In Malaysia. Journal of Global Business and Social Entrepreneurship (GBSE), 2(5).

Samuri, V. I.F., Soegoto, A. S., \& Woran, D. (2018). Studi Deskriptif Motivasi Belanja Hedonis pada Konsumen Toko Online Shopee. Jurnal EMBA, 2239-2245.

Sidharta, I., \& Suzanto, B. (2015). Pengaruh Kepuasan Transaksi Online Shopping dan Kepercayaan Konsumen Terhadap Sikap Serta Perilaku Konsumen Pada E-commerce. Jurnal Computech \& Bisnis, 23-26.

Sukma, A. A. (2012). Analisis Faktor - Faktor Yang Mempengaruhi Keputusan Pembelian Melalui Social Networking Websites. Ekonomi Manajemen, 2(1). 
Tai, J., \& Chew., \&. (2012). Brand Management. Indeks.

Triwidyastika, A. (2012). Studi Tentang Pengaruh Persepsi Manfaat Dan Persepsi Resiko Terhadap Sikap Pada Belanja Online Dan Implikasinya Pada Minat Belanja Online Di D'Shetwo Boutique. Jurnal Sains Pemasaran Indonesia, XI(1), 51-75.

Witami, Dewa Ayu Dita, dan Suartana, I. W. (2019). Pengaruh Persepsi Kegunaan, Kemudahan Penggunaan dan Risiko Terhadap Minat Mahasiswa Menggunakan Sistem Blockchain. EJurnal Akuntansi, 28(2).

Yunus, N. N., Rashid, W. E., Ariffin, N. M., \& Rashid, N. M. (2014). Muslim's Purchase Intention towards Non-Muslim's: Halal Packaged Food Manufacturer. Procedia - Social and Behavioral Sciences, 130, 145-154.

Zalni, Z. R. \& A. (2019). Pengaruh Reputasi, Electronic Word of Mouth dan Web Quality Terhadap Kepercayaan Pelanggan Shopee di Kota Padang. Jurnal Kajian Manajemen Dan Wirausaha, 01(02), 97-107. 